\title{
Effect of PPFM and PGRs on Root Characters, TDMP, Yield and Quality of Tomato (Solanum lycopersicum) under Drought
}

\author{
R. Sivakumar*, P. Chandrasekaran and S. Nithila \\ Department of Crop Physiology, Tamil Nadu Agricultural University, India \\ *Corresponding author
}

\section{A B S T R A C T}

\section{Keywords}

PPFM,

Brassinolide,

Salicylic acid, Root length, SLW, Yield,

Lycopene, Tomato

\section{Article Info}

Accepted:

16 February 2018

Available Online:

10 March 2018

\begin{abstract}
Water is precious and water scarcity is the major cause of drought. Indian agriculture primarily depends on irrigation facilities and drought is threatening when the country's population is increasing rapidly. Due to climate change, drought adversely affect on agricultural production by lowering the produce. An experiment was conducted to assess the impact of PPFM (Pink Pigmented Facultative Methylotroph) and PGRs on alleviating the drought stress effects on tomato through root characters, yield and quality. Pot culture experiment was carried out in tomato variety PKM 1 with foliar spray of PPFM (1\%), PPFM (2\%), PPFM (3\%) and growth regulators like brassinolide (1 ppm), salicylic acid $(100 \mathrm{ppm})$, benzyl amino purine $(100 \mathrm{ppm})$ and gibberellic acid $(10 \mathrm{ppm})$ under drought condition created based on field capacity of soil. 50 per cent field capacity was maintained throughout the growth period for induction of drought and 100 per cent field capacity maintained as absolute control. The study indicated that the PPFM and PGRs could be effectively improving drought tolerance capacity of tomato crop under drought. Among the PGRs and different concentrations of PPFM used, PPFM (2\%) was found to superior in improving root characters and yield. The highest root length of $25.9 \mathrm{~cm}$ was registered by PPFM (2\%) which has the ability to protect the plant under drought. Foliar spray of $2 \%$ PPFM recorded highest specific leaf weight (5.96) followed by $100 \mathrm{ppm}$ salicylic acid (5.66). The higher fruit yield of $552.9 \mathrm{~g}$ was maintained by PPFM (2\%) followed by brassinolide (509.4) under drought. PPFM (2\%) registered it s supremacy on higher lycopene content (5.92) followed by brassinolide (5.88).
\end{abstract}

\section{Introduction}

Tomato (Solanum lycopersicom) belongs to the family solanaceae and important vegetable crop $\mathrm{w}$ is a good source of vitamins A, B and C. The popularity of tomato is rising among consumers because of its good taste, high level of lycopene and beta-carotene, which are good anti-oxidants. Although tomato is a day neutral plant, which is highly susceptible to high temperature (Malik and Bashir, 1994) and drought. India is the second largest producer of tomato accounting for $11.10 \%$ of the world's production. According to the fifth assessment report of IPCC (2014), drought is the significant impact of current climate related extremes. In India, drought is a regular problem which affects agriculture production 
and life of animals and humans frequently. Water is the most limiting factor for plant growth. If plants do not receive adequate water, the resulting drought stress can reduce growth more than all other environmental stresses combined (Khan et al., 2015).

Drought is the most important environmental stress in agriculture and many efforts have been made to improve crop yield under drought. While natural selection has favoured mechanisms for adaptation and survival, breeding activity has directed selection towards increasing the yield of crops. Meanwhile, foliar application of PGRs can be used to mitigate the negative effect of drought on crops through physiological approaches.

Farjam et al., (2013) suggested that the foliar spray of salicylic acid significantly increased the proline content and improves drought tolerant capacity of chick pea under drought stress condition. Foliar spray of PPFM (2\%) was found to superior in improving relative water content, photosynthetic rate, SPAD value, proline content ultimately improve the drought tolerant capacity in tomato (Sivakumar et al., 2017). Extensive research over the years' has established stress-impactmitigating role of brassinosteroids and associated compounds in different plants exposed to various abiotic stresses such as high temperature and drought (Mahesh et al., 2013). Chandrasekaran et al., (2017) reported that the PPFM (2\%) and brassinolide (1 ppm) treatments were found to superior in improving germination associated traits, stress tolerant index and anti-oxidant enzyme catalase activity which have the ability to protect the plant under abiotic stress condition. Peleg et al., (2011) found over expression of ipt gene which is responsible for cytokinin synthesis improves the drought tolerance in different plants. Hence, the present study was conducted to mitigate the drought effect on tomato by using PPFM and
PGRs through assessing root characters, yield and quality.

\section{Materials and Methods}

The experiment was carried out in the pot culture under glass house condition. Red sandy soil was used for pot culture experiment. Soil mixture was prepared by using red soil, vermicompost and sand in the ratio of 3:2:1. Drought was imposed at first day after transplanting onwards by maintaining soil moisture at 50 per cent field capacity for drought stress. The experiment was laid out in completely randomized block design with three replications. The treatments like absolute control (100\% FC), Control (50\% FC), PPFM (1\%), PPFM (2\%), PPFM (3\%), brassinolide (1 ppm), salicylic acid (100 ppm), benzyl amino purine (100 ppm) and $\mathrm{GA}_{3} \quad(10 \mathrm{ppm})$ were used for this experiment. PPFM and PGRs treatments were given as foliar spray at 25 and 45 days after transplanting.

The plant was uprooted from the pot and the root was taken with minimum damage and the length from the cotyledonary node to the root tip was measured and expressed as $\mathrm{cm}$. The root volume was estimated by water displacement method.

Individual plant roots were immersed in known volume of water and the amount of water displaced was measured and expressed in cubic centimeter. Uprooted plant samples, after washing the root portion, were first shade dried and then oven dried at $80^{\circ} \mathrm{C}$ for 48 hours. Transverse hand sections, approximately 0.2 to $0.5 \mathrm{~mm}$ thickness were made with a razor blade from roots and taken for Scanning Electron Microscopy (SEM) using a FEI QUANTA 250 ESEM. In the anatomical cross sections the length and width of treachery cells were measured. 
The dry weight of the whole plant was recorded and expressed as $g$ plant ${ }^{-1}$. Specific leaf weight was calculated by using the formula of Pearce et al., (1968) and expressed in $\mathrm{mg} \mathrm{cm}$. The total weight of fruits harvested from each plant of all picking was added and average yield per plant was worked out and expressed in gram per plant.

The total soluble content in the pulp was determined by using a hand refractometer and expressed in ${ }^{\circ}$ Brix. Lycopene content of the fruit was estimated by using petroleum ether and OD of the extract was measured at 503 $\mathrm{nm}$ in UV-VIS spectrophotometer using petroleum ether as blank (Ranganna, 1986). Ripened fruit samples were analyzed for the ascorbic acid content, using 2, 6 dichlorophenol indophenol dye titrimetrically as per AOAC (2000).

Two gram of sample was blended with $10 \mathrm{ml}$ of 4 per cent oxalic acid and filtered through muslin cloth. Two $\mathrm{ml}$ of extract titrated against 2, 6 - dichlorophenol indophenol dye till the pink colour end point which persisted for at least 15 seconds $\left(\mathrm{TV}_{2}\right)$. Similar procedure was followed against standard solution made in 4 per cent oxalic acid to get standard titre value $\left(\mathrm{TV}_{1}\right)$. The ascorbic acid content in the fruit was calculated by using following formula.

Ascorbic acid $=$

Ascorbic acid in standard $\mathrm{x} \mathrm{TV}_{2} \mathrm{x}$ Total sample volume $\mathrm{x} 100$

Volume taken $\mathrm{x} \mathrm{TV}_{1} \mathrm{x}$ Weight of the sample

The data on various parameters were analyzed statistically as per the procedure suggested by Gomez and Gomez (1984). Wherever the treatment differences are found significant, critical differences were worked out at five per cent probability level and the values were furnished.

\section{Results and Discussion}

\section{Impact of PPFM and PGRs on root characters under drought}

Root length plays a major role in the absorption of water and nutrients necessary for normal plant growth. The reduction of root growth is a result of the inhibition of cell cycle progression and reduction in root apical meristem size (West et al., 2004). The present investigation showed that the root length was decreased up to 51.19 per cent under drought stress over absolute control. The application of PGRs invariably reduced the per cent reduction of root length under drought which leads to increasing the water uptake.

The maximum root length was recorded in absolute control $(27.90 \mathrm{~cm})$ and minimum in control of $13.50 \mathrm{~cm}$. Among the treatments, PPFM (2\%) marked the highest root length of $25.90 \mathrm{~cm}$, followed by brassinolide $(25.20$ $\mathrm{cm})$ and salicylic acid $(22.93 \mathrm{~cm})$. Root length was increased up to 26.34 per cent by PPFM (2\%) higher than control followed by brassinolide (22.93\%) (Table 1). Chandrasekaran et al., (2017) found that the treatment with PPFM (2\%) recorded higher root length followed by gibberellic acid and salicylic acid in tomato. This increment by PPFM might due to, methylobacterium are capable to generate plant growth regulators such as auxin and cytokinin (Ivanova et al., 2000) which induce cell division and cell elongation. Clouse (2011) reported that application of brassinosteroids increase the root growth under drought might be due to it stimulates ethylene biosynthesis and triggers ethylene responses in roots.

Highest root volume was observed in absolute control $(122.80 \mathrm{cc})$ whereas in control $(97.90$ cc) recorded lowest (Table 1). Among the PGRs, salicylic acid (119.70 cc) registered highest root volume followed by brassinolide 
(118.90 cc) and PPFM (2\%) treatment (117 cc). Salicylic acid exhibited increased root volume up to 22.33 per cent compared to control under drought condition followed by brassinolide $(21.45 \%)$. The foliar spray of PGRs and PPFM helps to alleviate drought with improving the lateral root growth which increased the root volume.

Roots, the primary organs for the absorption of water and minerals, ironically offer the greatest resistance to liquid water flow in the soil-plant interphase simply to regulate the absorption process with minimum energy (Rieger and Litvin, 1999). In the present study showed pictorial representation of SEM root cross section, whole view of the root showed smaller in size $(61.56+55.65 \mu \mathrm{m})$ observed in control compared to absolute control (104 $+61.6 \mu \mathrm{m})$. Changes in the size of tracheary elements and change in their organization as aggregation of xylem vessel elements was obvious (Wolf et al., 2012). Similarly, present study, PPFM (2\%) treatment $(94.32+81.09$ $\mu \mathrm{m})$ showed larger tracheary element size in terms of length and width grown under drought stress (Fig. 1) followed by brassinolide $(63.15+56.79 \mu \mathrm{m})$.

One of the most functional aspects related to root anatomy is water and nutrient transport capacity, because it is highly influenced by the number and size of the water conducting elements (Steudle and Peterson, 1998). Root water uptake of the whole plant is a function of both hydraulic conductivity and water potential gradient across the root or the whole plant. Crop plants are better equipped with an appropriate type of anatomy, largely constitutive in nature, to cope with the surrounding environment (Rieger and Litvin, 1999). However, Purushothaman et al., (2013) reported that the number and size of the xylem vessels and other xylem components seem to increase with water scarcity.

\section{Impact of PPFM and PGRs on TDMP and SLW under drought}

The analysis on the total dry matter production per plant revealed that absolute control have more dry matter production compared to drought plant. In the present study, TDMP was decreased up to 27.70 per cent by drought when compared to absolute control (Table 1). Drought stress suppressed the plant height, leaf number, size and tillers which finally lowered the dry matter production (Khan and Abdullah, 2003). Water availability is the key factor for dry matter production in plant. Low water availability decreases water and nutrient uptake, photosynthetic rate and translocation of photo assimilates. Nahar et al., (2011) showed reduction in dry matter production under water deficit condition in four tomato genotypes.

Among the PGRs and PPFM, salicylic acid showed the more TDMP of $91.06 \mathrm{~g} \mathrm{plant}^{-1}$ followed by brassinolide $\left(90.51 \mathrm{~g} \mathrm{plant}^{-1}\right)$ and 2\% PPFM (88.67 $\mathrm{g} \mathrm{plant}^{-1}$ ). In the present study, it was observed that foliar spray of salicylic acid increased the TDMP by 33.54 per cent compared to control followed by brassinolide $(32.73 \%)$.

Zhang et al., (2008) found that application of BRs could partially alleviate the detrimental effect of water stress on growth of soybean through improving antioxidant system and promoting dry matter accumulation. Seed treatment or foliar application of chemicals like kinetin, salicylic acid increased the yield of different crops due to reduction in stress induced inhibition of plant growth and plant dry matter production (Khan et al., 2003).

SLW is to assess the translocation efficiency of crop plants. Due to drought stress, 29.90 per cent of SLW was reduced when compared to absolute control. Highest specific leaf 
weight of $6.08 \mathrm{mg} \mathrm{cm} \mathrm{cm}^{-2}$ was observed in absolute control and the lowest was recorded in control $\left(4.26 \mathrm{mg} \mathrm{cm} \mathrm{cm}^{-2}\right.$ ). Among the treatments, PPFM (2\%) showed higher specific leaf weight of $5.96 \mathrm{mg} \mathrm{cm}^{-2}$. Among the PGRs, PPFM (2\%) showed 28.52 per cent increment of SLW followed by brassinolide (Fig. 2). The enhancement of SLW by brassinolide and PPFM (2\%) might be due to involvement in the translocation of photo assimilates from source to sink.

\section{Impact of PPFM and PGRs yield under drought}

Absolute control significantly recorded the highest fruit yield of $674.10 \mathrm{~g}$ and control recorded the least value of $300.30 \mathrm{~g}$. Foliar spray of 2\% PPFM documented significantly superior fruit yield of $552.90 \mathrm{~g}$ which is closely followed by brassinolide (509.40 g) and salicylic acid (472.60 g). Wang et al., (2003) reported that drought is a serious environmental stress which affects agriculture productivity and yield more than 50 per cent. In the present study, $64.70 \%$ of yield was reduced by drought stress (Table 2). Jaleel et al., (2008) observed that drought is one of the serious environmental factor affecting yield and quality. Water stress inhibits cell enlargement and cell division ultimately reduces plant growth by affecting various physiological and biochemical processes. Yield showed positive response to PGRs and PPFM under water deficit condition. PGRs help in mitigation of water stress and reduced the per cent reduction in yield in wheat (Shah and Paulsen, 2011). In the present study, fruit yield increased up to 35.00 per cent by PPFM (2\%) followed by brassinolide (24.50\%).

Table.1 Effect of PGRs and PPFM on root characters and TDMP of tomato under drought

\begin{tabular}{|c|c|c|c|c|}
\hline S. No. & Treatments & Root length (cm) & Root Volume (cc) & TDMP $\left(\right.$ g plant $\left.^{-1}\right)$ \\
\hline 1 & Absolute control (100\% FC) & 27.90 & 122.80 & 94.27 \\
\hline 2 & Control ( $50 \%$ FC) & 20.50 & 97.90 & 68.19 \\
\hline 3 & PPFM (1\%) & 22.60 & 101.00 & 66.36 \\
\hline 4 & PPFM (2\%) & 25.90 & 117.00 & 88.67 \\
\hline 5 & PPFM (3\%) & 22.10 & 110.90 & 65.49 \\
\hline 6 & Brassinolide (1 ppm) & 25.20 & 118.90 & 90.51 \\
\hline 7 & Salicylic acid (100 ppm) & 22.93 & 119.70 & 91.06 \\
\hline 8 & BAP (100 ppm) & 21.50 & 108.70 & 74.32 \\
\hline 9 & $\mathrm{GA}_{3}(10 \mathrm{ppm})$ & 22.10 & 106.76 & 76.48 \\
\hline & SEd & 0.48 & 2.73 & 1.95 \\
\hline & $\mathrm{CD}(\mathrm{P}=\mathbf{0 . 0 5})$ & 1.02 & 5.73 & 4.09 \\
\hline
\end{tabular}


Table.2 Effect of PGRs and PPFM on yield and quality parameters of tomato under drought

\begin{tabular}{|c|c|c|c|c|}
\hline S. No. & Treatments & Fruit yield (g) & TSS ( ${ }^{\circ}$ Brix) & $\begin{array}{l}\text { Ascorbic acid } \\
\left(\mathrm{mg} 100 \mathrm{~g} \mathrm{~g}^{-1}\right)\end{array}$ \\
\hline 1 & Absolute control (100\% FC) & 674.10 & 6.20 & 28.92 \\
\hline 2 & Control (50\% FC) & 409.30 & 5.00 & 24.36 \\
\hline 3 & PPFM (1\%) & 462.40 & 5.60 & 25.93 \\
\hline 4 & PPFM (2\%) & 552.90 & 5.90 & 27.32 \\
\hline 5 & PPFM $(3 \%)$ & 428.80 & 5.10 & 25.87 \\
\hline 6 & Brassinolide (1 ppm) & 509.40 & 6.00 & 24.78 \\
\hline 7 & Salicylic acid (100 ppm) & 472.60 & 5.40 & 26.02 \\
\hline 8 & BAP (100 ppm) & 419.20 & 5.80 & 26.65 \\
\hline \multirow[t]{3}{*}{9} & $\mathrm{GA}_{3}(10 \mathrm{ppm})$ & 425.60 & 5.10 & 25.34 \\
\hline & SEd & 11.03 & 0.12 & 0.48 \\
\hline & $\mathrm{CD}(\mathrm{P}=\mathbf{0 . 0 5})$ & 23.18 & 0.24 & 1.02 \\
\hline
\end{tabular}

Fig.1 Effect of PPFM on SEM root cross section of tomato under drought
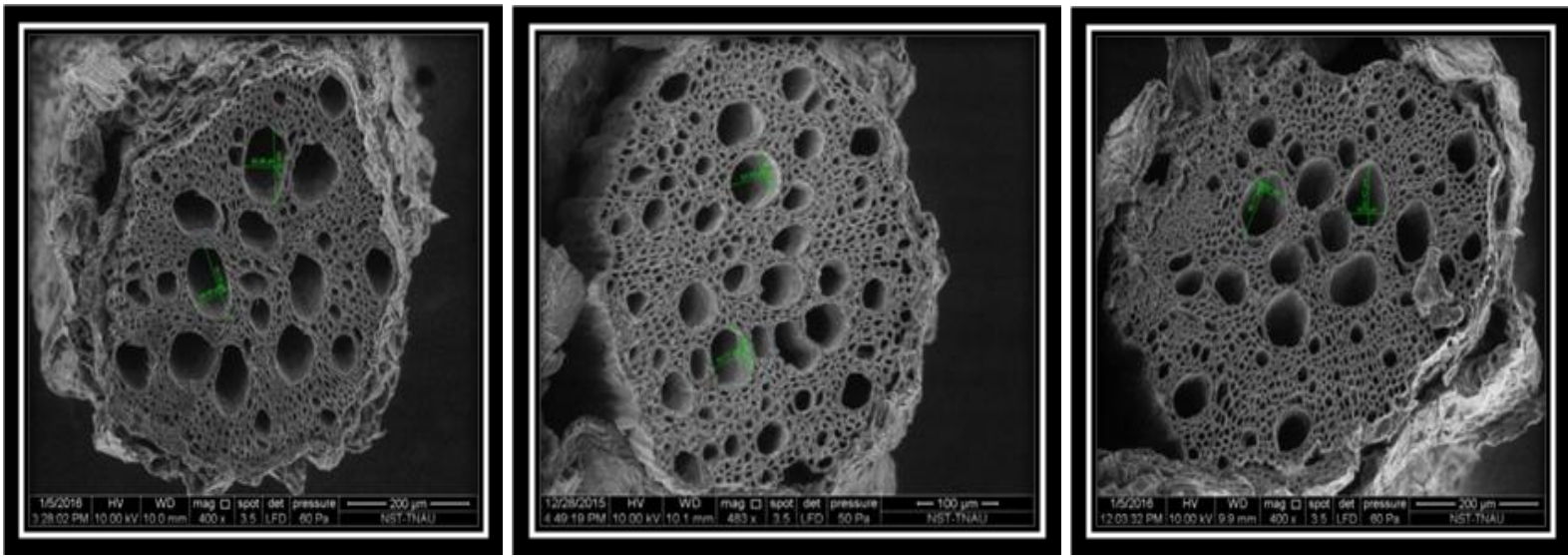

Absolute Control (100 FC) Control (50\% FC) PPFM (2\%) spray 
Fig.2 Effect of PGRs and PPFM on specific leaf weight of tomato under drought

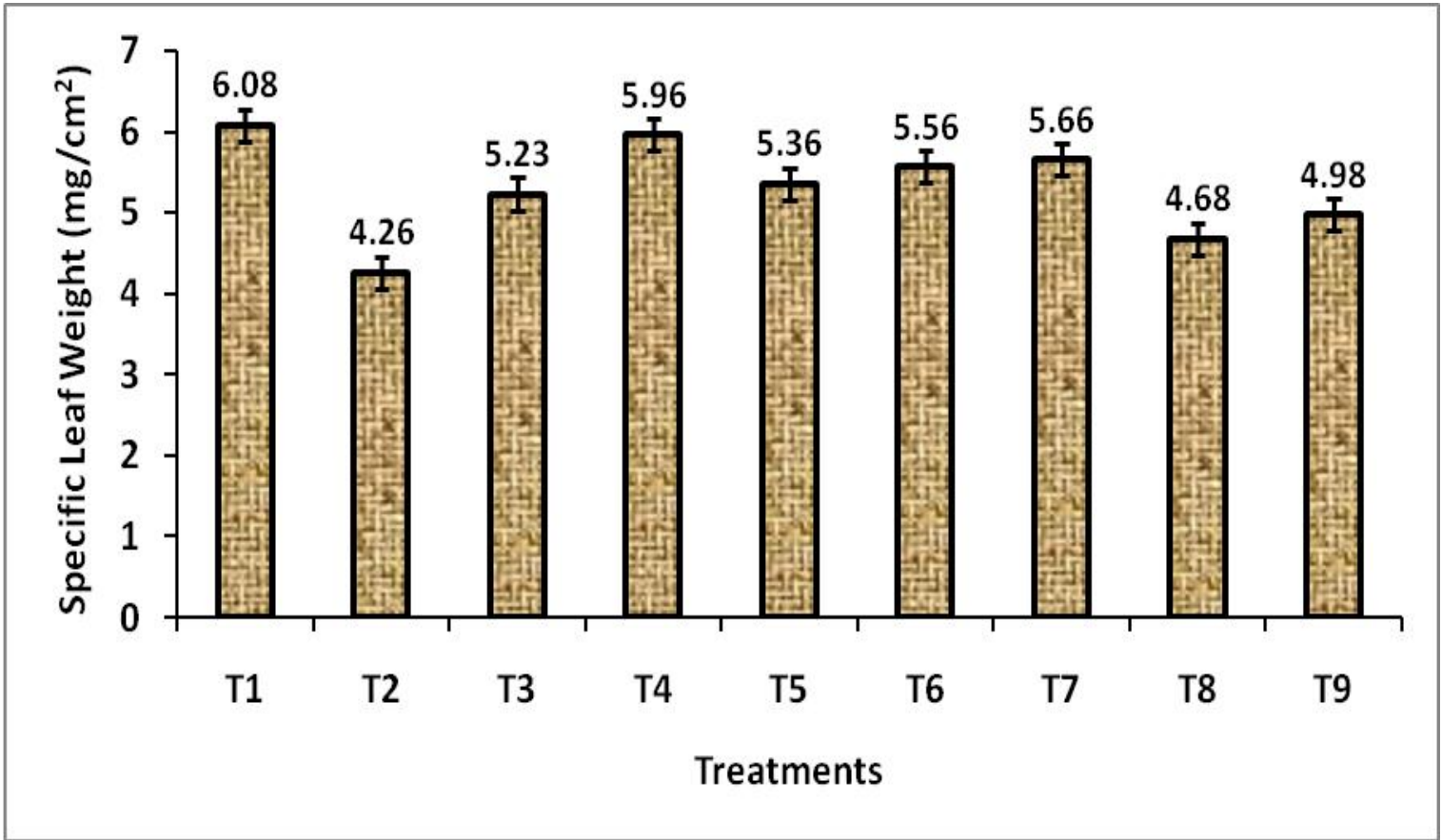

$\mathrm{T}_{1}$ : Absolute control (100\% FC); $\mathrm{T}_{2}$ : Control (50\% FC); $\mathrm{T}_{3}$ : PPFM (1\%); $\mathrm{T}_{4}:$ PPFM (2\%); $\mathrm{T}_{5}$ : PPFM (3\%); $\mathrm{T}_{6}$ : Brassinolide (1 ppm); $\mathrm{T}_{7}$ : Salicylic acid (100 ppm); $\mathrm{T}_{8}$ : $\mathrm{BAP}(100 \mathrm{ppm}) ; \mathrm{T}_{9}: \mathrm{GA}_{3}(10 \mathrm{ppm})$

Fig.3 Effect of PGRs and PPFM on lycopene content of tomato fruit under drought

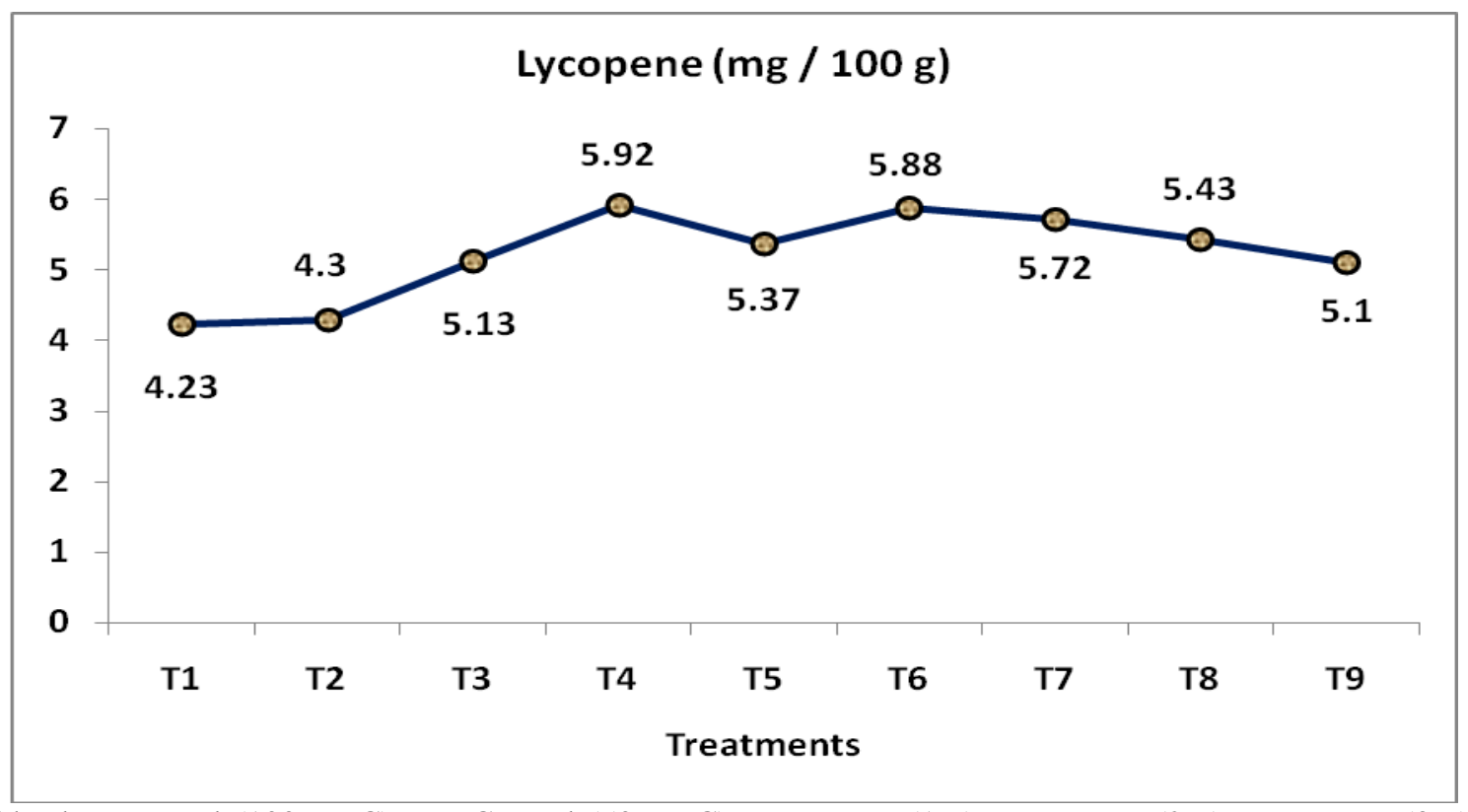

$\mathrm{T}_{1}$ : Absolute control (100\% FC); $\mathrm{T}_{2}$ : Control (50\% FC); $\mathrm{T}_{3}$ : PPFM (1\%); $\mathrm{T}_{4}:$ PPFM (2\%); $\mathrm{T}_{5}$ : PPFM (3\%); $\mathrm{T}_{6}$ : Brassinolide (1 ppm); $\mathrm{T}_{7}$ : Salicylic acid (100 ppm); $\mathrm{T}_{8}$ : BAP (100 ppm); $\mathrm{T}_{9}: \mathrm{GA}_{3}(10 \mathrm{ppm})$ 


\section{Impact of PPFM and PGRs on lycopene, ascorbic acid and TSS}

Lycopene is a key quality parameter in tomato which plays an important role in biosynthesis of carotenoids. It is responsible for red color in tomato fruit and acts as an antioxidant. It has a specific role in defense mechanism against environmental stress by scavenging peroxyl radicals and quenching singlet oxygen. Giannakoula and Ilias (2013) found there was a significant increase in lycopene content under drought in tomato. In the present study, 1.62 per cent of lycopene content was increased under drought compared to absolute control (Fig. 3). Among the PGRs and PPFM used, PPFM (2\%) ranked first with $5.92 \mathrm{mg}$ of lycopene followed by brassinolide (5.88).

However, ascorbic acid content decreased 18.72 per cent under drought stress condition over absolute control in the present experiment. In contrast, early findings by Tambussi et al., (2000) who reported that the increase in ascorbic acid might be an effective strategy to protect membranes from oxidative damage in stressed condition. However, in present study, PPFM (2\%) treatment increases 12.15 per cent ascorbic acid level. The similar result was found in tomato (Kumar et al., 2014). Total soluble solids decreased under drought stress condition up to 24 per cent over absolute control (Table 2). Among the treatments used, brassinolide increased the TSS by 20 per cent over control followed by PPFM (2\%) treatment (18\%).

\section{References}

AOAC, 2000. Official Methods of Analysis. $15^{\text {th }}$ ed. Association of Official Analytical Chemists, Arlington, VA.

Chandrasekaran, P., Sivakumar, R. Nandhitha, G.K. Vishnuveni, M. Boominathan, P. and Senthilkumar, M. 2017. Impact of PPFM and PGRs on seed germination, stress tolerant index and catalase activity in tomato (Solanum lycopersicum L) under drought. Inter. J. of Current Microbiol. and App. Sci. 6 (6): 540-549.

Clouse, S. D. 2011. Brassinosteroid signal transduction: From receptor kinase activation to transcriptional networks regulating plant development. Plant Cell. 23: 1219-1230.

Farjam, S., Siosemardeh, A. Kazemi-Arbat, H. Yarnia, M. and Rokhzadi, A. 2013. Response of chickpea (Cicer arietinum L.) to exogenous salicylic acid and ascorbic acid under vegetative and reproductive drought stress conditions. J. of Appl. Bot. and Food Quality. 87: 80 - 86.

Giannakoula, A. E. and Ilias, I. F. 2013. The effect of water stress and salinity on growth and physiology of tomato (Lycopersicon esculentum Mill). Archives Biol. Sci. 65 (2): 611-620.

Gomez, K. A. and Gomez, A. A. 1984. Statistical procedures for agricultural research. (2nd Ed.) John Wiley and sons, New York, USA.

Ivanova, E. G., Dornina, N. V. Shepelyakovskaya, A. O. Laman, A. G. Brovko, F. A. and Trotsenko, Y. A. 2000. Facultative obligate aerobic methylobacteria synthesize cytokenins. Microbiol. 69: 646-651.

Jaleel, C. A., Gopi, R. and Panneerselvam, R. 2008. Growth and photosynthetic pigments responses of two varieties of Catharanthus roseus to triadimefon treatment. Comp. Rend. Biol. 331: 272-277.

Khan, M. A. and Abdullah, J. Z. 2003. Salinitysodicity induced changes in reproductive physiology of rice (Oryza sativa) under dense soil conditions. Environ. Exp. Bot. 49: 145-157.

Khan, S.H., Khan, A. Litaf, U. Shah, A.S. Khan, M.A. Bilal, M. and Ali, M.U. 2015 Effect of Drought Stress on Tomato cv. Bombino. J. Food Process. and Technol. 6 (7): 465470

Khan, W., Prithviraj, B. and Smith, D. L. 2003. Photosynthetic responses of corn and soybean to foliar application of salicylates. J. Plant Physiol. 160: 485-492.

Kumar, A., Biswas, T. K. Singh, N. and Lal, E. P. 2014. Effect of gibberellic acid on growth, 
quality and yield of tomato (Lycopersicon esculentum Mill). IOSR - JAVS.7 (7): 2830.

Mahesh, B., Parshavaneni, B. Ramakrishna, B. and Rao, S. S. R. 2013. Effect of brassinosteroids on germination and seedling growth of radish (Raphanus sativus L.) under PEG-6000 induced water stress. Am. J. Plant Sci. 4: 2305-2313.

Malik, M. and Bashir, E. 1994. Horticulture. National Book Foundation, USA.

Nahar, K., Ullah, S. M. and Islam, N. 2011. Osmotic adjustment and quality responses of five tomato cultivars (Lycopersicon essculentum Mill) following water deficit stress under subtropical climate. Asian J. Plant Sci. 10 (2): 153-157.

Pearce, R. B., Brown, R. H. and Balaster, R. E.. 1968. Photosynthesis of alfalfa leaves as influenced by environment. Crop Sci. 36: 677-680.

Peleg, Z., Reguera, M. Tumimbang, E. Walia, H. and Blumwald, E. 2011. Cytokininmediated source/sink modifications improve drought tolerance and increase grain yield in rice under water-stress. Plant Biotechnol. J. 9: 747-758.

Purushothaman, R., Zaman-Allah, M. Mallikarjuna1, N. Pannirselvam, R. Krishnamurthy, L. and Laxmipathi Gowda, C. L. 2013. Root anatomical traits and their possible contribution to drought tolerance in grain legumes. Plant Prod. Sci. 16 (1): 18.

Ranganna, S. 1986. Hand book of analysis and quality control for fruit and vegetable products. New Delhi: McGraw Hill Publishing Co. Ltd.

Rieger, M. and Litvin, P. 1999. Root system hydraulic conductivity in species with contrasting root anatomy. J. Exp. Bot. 50: 201-209.

Shah, N. H. and Paulsen, G. M. 2011. Interaction of drought and high temperature on photosynthesis and grain filling of wheat. Plant Soil. 257: 219-226.

Sivakumar, R., Nandhitha, G. K. Chandrasekaran, P. Boominathan, P. and Senthilkumar, M. 2017. Impact of pink pigmented facultative methylotroph and PGRs on water status, photosynthesis, proline and NR activity in tomato under drought. Inter. J. of Current Microbiol. and App. Sci. 6 (6): 1640-1651.

Steudle, E. and Peterson, C. A. 1998. How does water get through roots? J. Exp. Bot. 49: 775-788.

Tambussi, E. A., Bartoli, C. G. Beltrano, J. Guiamet, J. J. and Araus, J. L.. 2000. Oxidative damage to thylakoid proteins in water-stressed leaves of wheat (Triticum aestivum). Physiol. Planta. 108: 398-404.

Wang, W., Vinocur, B. and Altman, A. 2003. Plant responses to drought, salinity and extreme temperatures: towards genetic engineering for stress tolerance. Planta. 218: 1-14.

West, G., Inze, D. and Beemster, G. T. S. 2004. Cell cycle modulation in the response of the primary root of Arabidopsis to salt stress. Plant Physiol. 135: 1050-105.

Wolf, S., Hematy, K. and Hofte, H. 2012. Growth control and cell wall signaling in plants. Annu. Rev. Plant. Biol. 63: 381-407.

Zhang, M., Zhai, Z. Tian, X. Duan, L. and Li, Z. 2008. Brassinolide alleviated the adverse effect of water deficit on photosynthesis and the antioxidant of soybean (Glycine max L.). Plant Growth Regul. 56: 257-264.

\section{How to cite this article:}

Sivakumar, R., P. Chandrasekaran and Nithila, S. 2018. Effect of PPFM and PGRs on Root Characters, TDMP, Yield and Quality of Tomato (Solanum lycopersicum) under Drought. Int.J.Curr.Microbiol.App.Sci. 7(03): 2046-2054. doi: https://doi.org/10.20546/ijcmas.2018.703.240 